\title{
AGRONEGOCIO Y CORPORACIONES TRANSNACIONALES Modelando el Uruguay dependiente
}

\author{
Paula Florit O'neill \\ Maximiliano Piedracueva Coronel \\ Universidad de la República, Uruguay
}

http://dx.doi.org/10.5209/NOMA.54345

\begin{abstract}
Resumen.- El presente artículo se propone analizar el modelo de desarrollo del Uruguay bajo un enfoque de las corrientes de la dependencia. El supuesto base del trabajo es que en las primeras décadas del Siglo XXI el país mantiene una condición de dependencia frente a unas transformadas corporaciones transnacionales. Como herramental teórico se toma la propuesta de Kaplan sobre las corporaciones transnacionales, no como un reflejo de su estudio sino como categorías iluminadoras de un nuevo sistema mundo.
\end{abstract}

Palabras clave: Dependencia, agronegocio, corporaciones transnacionales

Abstract.- This article analyzes the development model of Uruguay with a focus on the dependence's theories. Work hypothesis is that in the first decades of the XXI century the country maintains a condition of dependence on a transformed transnational corporations. Our theoretical tooling is the proposal of Kaplan about transnational corporations, not as a reflection of their study but as enlightening categories of a new world system.

Key words: Dependence, agribusiness, transnational corporations

\section{La perspectiva dependentista como herramental teórico.}

Retomar las teorías de la dependencia luego de décadas de su aparición, de un camino empedrado y para algunos, sepultado, viene a reafirmar la vigencia de su problema más que de sus soluciones. Como se ha expuesto en otro trabajo "el resurgimiento de las teorías de la dependencia en el S. XXI puede explicarse por una pregunta más que por una afirmación żqué tan distintas son las condiciones actuales entre los países latinoamericanos y los países desarrollados de lo que vislumbraron los latinoamericanos en la década del "60?" (FLORIT y PIEDRACUEVA, 2012: 2)

Atilio Borón (1998) ha expresado que "nuestros estados son hoy mucho más dependientes que antes, agobiados como están por la deuda externa y por una 'comunidad financiera internacional' que en la práctica los despoja de su soberanía." (Citado por BEIGEL, 2006:306) Junto con la reaparición de teóricos de la dependencia que re plantean el problema teórico inicial, existen algunos nuevos enfoques que, si bien no se encuadran dentro de la teoría de la dependencia, 
comparten su objeto de estudio. En este sentido las propuestas del neocolonialismo (NASH, 1977) y la revitalización de las teorías del imperialismo (LEA, 1988), los aportes conceptuales de Samir Amin (1989), y la conformación teórica del Sistema-Mundo en su versión neo-colonial de Quijano (1992, 2000) o de economía-mundo de Wallerstein (1998, 2005), son algunas de las visiones que problematizan la condición actual de los países latinoamericanos frente al sistema de acumulación. En concreto, todas estas visiones cuestionan las posibilidades de desarrollo de los países periféricos, atrasados o subdesarrollados en el actual sistema de acumulación mundial. Reconociendo que difieren en sus conclusiones se ha de señalar que sus ejes de análisis confluyen en gran parte.

En este trabajo nos proponemos impensarl las teorías de la dependencia, retomar su problema y analizarlo a la luz de categorías que se fundamentan teórica y políticamente para el caso uruguayo. En concreto, se toma aquí la propuesta analítica de Kaplan sobre la transnacionalización de la economía y sobre sus impactos en la economía y política nacional ${ }^{2}$. El autor identifica cuatro dimensiones a partir de las cuales pueden entenderse los efectos de esta transnacionalización para las economías dependientes. En primer lugar una "naturaleza de las corporaciones transnacionales", devenida de su impronta multinacional. Esta naturaleza supone una desigual inserción en los países, favoreciendo las economías centrales por lo que mantienen vínculos con los Estados centrales, mientras las economías periféricas se mantienen en posiciones subalternas, con importante fuga de capitales y con Estados altamente cooptados por la envergadura de estas empresas transnacionales.

La segunda dimensión es denominada "especialización deformante" y alude a una capacidad de estas empresas de posicionarse en los puntos clave de las economías periféricas, invirtiendo en el avance tecnológico y la especialización de un sector de la economía, a la vez que el resto de la economía local se mantiene con un escaso estímulo e inversión. De esta forma se gesta en los países periféricos una especialización y una inversión diferencial que deviene en una economía a dos velocidades, donde convive la tecnología y el

\footnotetext{
'Wallerstein (1998) aplica la categoría de "impensar" aludiendo a la necesidad de abandonar el análisis y estudio de las tradiciones teóricas en las aplicaciones particulares de sus gestores, para guiar la atención hacia los problemas centrales que estas tradiciones teóricas apelan estudiar.

2 Kaplan rehusaba a incluirse dentro de las teorías de la dependencia sin embargo su lectura y su propuesta comparten el problema teórico planteado por esta corriente. Debe señalarse que durante el siglo pasado se etiquetaba como dependencia a aquellos trabajos estructuralistas de la década del 60 y 70 como los de Cardozo y Faletto, GunderFrank, etc. No obstante muchos otros trabajos fueron posteriormente asimilados como los de Quijano, Furtado, Marini, entre otros; y actualmente se engloban los trabajos de Katz, Amin, Wallerstein, De Sousa Santos, Key, etc.
} 
desarrollo económico - productivo con amplios sectores atrasados tecnológicamente y pauperizados socialmente.

La "descapitalización" es la tercera dimensión identificada por Kaplan. Bajo este rótulo el autor identifica procesos por el cual los países periféricos pierden el acceso a capital autónomo y su independencia financiera por al menos tres vías. En primer lugar un proceso de déficit ocasionado en un intercambio comercial donde los países periféricos venden productos ricos en materia prima y consumen del exterior productor ricos en trabajo agregado. En segundo lugar, el hecho de que las empresas transnacionales se ubican en los países periféricos remitiendo hacia las economías centrales pero valiéndose frecuentemente de subsidios nacionales de la periferia. En tercer lugar por la alta dependencia de los préstamos internacionales que no sólo condicionan las políticas públicas nacionales sino que insertan a los países en una lógica de pago permanente de intereses.

La cuarta dimensión, la "subordinación colonial", se vincula estrechamente con la especialización deformante al basarse en la capacidad de estas empresas de posicionarse en puntos clave de la economía. Esta dimensión señala la capacidad de estas empresas de desarrollar cadenas y de ubicarse dentro de ellas en los puntos de control o dominio. De esta forma las cadenas están al servicio o son controladas por las empresas transnacionales, que a su vez se ubican a nivel global distribuyendo las especializaciones entre los países periféricos y centrales en función de las condiciones e intereses de la propia empresa, especialmente ubicando en el centro los desarrollos tecnológicos y en la periferia los aspectos más "extractivistas" de sus cadenas.

\section{Inserción internacional, "modelo país" y transnacionalización}

Analizar las transformaciones agrarias que se han sucedido en el Uruguay en las últimas décadas requiere e implica retirar levemente la mirada sectorial, ceñida al sector agropecuario, y ponderar las características del modelo de desarrollo imperante y hegemónico a nivel macro y global. A partir de la crisis mundial del año 1973 el globo se ha visto inmerso en un proceso de profundización de la globalización en la que los capitales financieros cobran un peso fundamental en la macroeconomía y en el comercio internacional.

Uno de los primeros impactos de esta transformación fue la masiva llegada de capitales foráneos a los países del denominado tercer mundo en calidad de inversiones y de endeudamiento público. Los reajustes neoliberales de la década del ' 80 y ` 90 del siglo pasado fueron la estrategia política y económica de reorganizar la división mundial del trabajo y de profundizar los lazos de dependencia y dominación entre 
los países "desarrollados" y los países en "desarrollo" y/o "subdesarrollados."

En este contexto de masiva circulación de capitales, a veces entendido como favorable, muchas otras entendido como de sentencia, el Uruguay no fue ajeno a la dinámica de endeudamiento público, a la reducción parcial del rol del Estado y el crecimiento exponencial de la pobreza y la miseria. La crisis regional latinoamericana a comienzos de la década del 2000 generó un punto de inflexión en los modelos económicos hegemónicos dando lugar a ciertos cambios institucionales, políticos y culturales que rearmarían un nuevo escenario en el continente. Estos cambios, materializados principalmente con el ascenso de los sectores de izquierda al poder, proyectaban un quiebre con el modelo neoliberal y prometían nuevos reajustes estructurales en pos de una sociedad más justa y equitativa.

Desde el año 2005 y hasta la fecha el Uruguay se encuentra bajo el gobierno de la coalición de izquierda, sin embargo un análisis detallado de las políticas diseñadas e implementadas dan cuenta de un modelo de gobierno, de país y de desarrollo, más cercano a un neodesarrollismo (KATZ, 2014) o al neoestructuralismo cepalino (SUNKEL, 1991) que a un modelo alternativo que ataque las causas generadoras de desigualdades e inequidades entre el Uruguay y sus pares estados, y a su interna entre los diversos grupos y sujetos.

Con antecedentes en la década del '70 del siglo pasado pero reforzándose continuamente hasta la actualidad el Uruguay ha tomado una Política de Estado de inserción internacional como país anfitrión de capitales extranjeros. En un primer momento como deuda pública, en una segunda etapa como Inversión Extranjera Directa (IED), el país se ha colocado a nivel mundial como una buena opción para capitales financieros debido a las exoneraciones impositivas y a la seguridad institucional que ofrece el gobierno uruguayo. En el pasado año, 2014, cinco de las principales calificadoras del Investment Grade calificaron al país con una nota BBB, la mejor calificación en la historia del país. ${ }^{3}$ Esta calificación es producto de innumerables variables y medidas entre las que se destaca el nuevo modelo de gestión de deuda del país, la institucionalización de la promoción de inversiones y el contexto internacional favorable a la producción uruguaya en tanto los precios de los productos agrícolas han presentado un incremento sostenido en la última década.

En este sentido, el motor de crecimiento del país está fuertemente basado en el ahorro externo como estímulo económico sin embargo no ha logrado que los impactos de tales inversiones transformen la matriz productiva del país (BITTENCOURT, 2009) y por tanto el rédito que se

\footnotetext{
3 http://www.presidencia.gub.uy/comunicacion/comunicacionnoticias/bergara-cincoprincipales-calificadoras-de-riesgo-le-otorgan-a-uruguay-grado-inversor
} 
obtiene no es óptimo, al tiempo que el crowding out presenta un balance negativo para el país (PELUFFO, 2011). Actualmente el modelo de IED es cuestionado ya que si bien ha incrementado el PBI existen elementos para cuestionar la sostenibilidad del modelo basado en la inversión extranjera en el Uruguay (BITTENCOURT 2009; BERRIEL; ESTAVILLO; BONJOUR, 2008, PELUFFO, 2011) Sin embargo el Uruguay mantiene su política de inserción internacional basada en la captación de capitales foráneos sin generar una reestructura institucional que permita un mejor aprovechamiento de tales divisas.

\section{Dependencia y capitalismo en el agro uruguayo}

El agro uruguayo se ha visto inmerso en esta serie de transformaciones principalmente por la circulación de capitales financieros hacia el sector agropecuario. La expansión de la frontera agrícola mundial que se sucede a partir de la emergencia de los gigantes asiáticos, del incremento de alimentos y del proceso de generación de biocombustibles, ha repercutido en que los países que, como Uruguay, basan su economía en la producción de bienes primarios de origen agropecuario se hayan vistos invadidos por un contingente de capitales externos en modalidades de inversión con destino a las actividades agropecuarias. La llegada de capitales foráneos con destino a la compra, arrendamiento e inversión en tierras ha trastocado la estructura agraria y productiva del país en forma radical. Tradicionalmente, la estructura productiva uruguaya tuvo como base la producción ganadera bovina integrando paulatinamente la producción ovina; la agricultura, horticultura y fruticultura fueron rubros menores en la historia del país (ASTORI, et al, 1982), hubo que esperar hasta la década de los '90 del siglo XX para que nuevos rubros comenzaran a tener un impacto mayor en la economía agropecuaria del mismo, en particular la expansión de la agricultura y el desarrollo de la forestación.

El incremento en la demanda de alimentos y el aumento en la demanda de energías alternativas han repercutido en una mayor demanda de tierras con nuevos usos y con nuevos agentes. La revolución tecnológica de los transgénicos impactó directamente en la productividad de la tierra y por tanto en el valor de la renta. Los suelos uruguayos destinados históricamente a la ganadería comenzaron a verse desplazados por la producción silvícola y agrícola con destino industrial. A partir de la Ley Forestal (15.939) del año 1987 el paisaje uruguayo se transformó pasando de campos naturales habitados por personas y animales a campos forestados, deshabitados y desolados. En el año 2013, según registros de la Dirección de Estadísticas Agropecuarias (DIEA) el Uruguay contaba con 1.841 .578 hectáreas forestadas de la cuales aproximadamente un millón son bosques con destino a la producción industrial de aserradero y celulosa, mientras que 
en los cultivos oleaginosos la superficie sembrada supera el millón de hectáreas para el mismo período (DIEA, 2014)

La llegada al país de empresas transnacionales como ENCE, STORA ENSO, Botnia (hoy UPM), Weyehaeuser y Montes del Plata dan cuenta de un modelo agroexportador transnacionalizado y directamente vinculado a una gran extensión de tierras del país mediante propiedad y arrendamiento. Junto con la promoción de las plantaciones forestales a través de la mencionada Ley Forestal, Uruguay se ha encaminado hacia la promoción del modelo general del agronegocio a través de la creación de distintos instrumentos y medidas de tipo político y económico. La Ley de Promoción de Inversiones (16.906), la profundización del régimen de zonas francas y puertos libres, la creación del Instituto Uruguay XXI, entre otras, han sido medidas directas que apuntan a complementar un buen servicio de captación de inversiones extranjeras.

En junio de 2013 ingresa al Parlamento uruguayo un proyecto de ley del Poder Ejecutivo que modifica el régimen actual de zonas francas pasándose a denominar Zonas Económicas Especiales. Actualmente el país cuenta con 13 Zonas Francas las que se incluirán en el nuevo régimen, y dentro de ellas, se encuentran la Zona Franca de Fray Bentos en la que opera UPM y la Zona Franca de Punta Pereira en la que opera Montes del Plata. Las modificaciones del régimen apuntan a levantar algunas restricciones en cuanto a al interés de inversión, en concreto, se promueven las inversiones descentralizadas, se incorporan las zonas al régimen aduanero, se reduce el porcentaje de mano de obra nacional en los desarrolladores de servicios (de un mínimo de $75 \%$ a un \%50, pudiendo ser menor en algunos casos), creación de Zonas Temáticas de Servicios, y la exoneración de todos los impuestos a excepción de IRAE4 y Seguridad Social a aquellas Zonas creadas fuera del área Metropolitana.

Este modelo particular se acompaña de la vigente Ley de Inversiones que institucionaliza una serie de beneficios fiscales a aquellos proyectos de inversión apoyados por el poder ejecutivo a través de la Comisión de Aplicación de la Ley de Inversiones (COMAP) Solamente en 2014 la COMAP avaló proyectos por una suma de US\$1.471.953.411 lo cual da cuenta del éxito de la política en términos de promoción, no obstante, aproximadamente el $10 \%$ del monto tiene como destinos actividades agropecuarias primarias apoyando la tesis citada del déficit en transformación de la matriz productiva del país. Junto con esto debe anotarse que en el año 2013 la IED en el país tuvo como destino a actividades primarias aproximadamente un $22 \%$ del total recibido. (CEPAL, 2013)

\footnotetext{
4 Impuesto a la Renta de las Actividades Empresariales
} 
Los grados de dependencia del modelo agroexportador serán analizados a la luz de las categorías aportadas por Kaplan y que permiten, a partir de la información disponible, dar cuenta de los niveles de restricción del país frente a las transnacionales.

\section{Cuatro dimensiones en la transnacionalización y la dependencia en Uruguay.}

\section{iv.i. La naturaleza de las corporaciones transnacionales.}

Kaplan en 1972 presenta las características de las corporaciones transnacionales que participan del proceso de inversión extranjera en Latinoamérica.Más allá de la lejanía temporal de la realidad observada por Kaplan y el Uruguay actual, la propuesta aquí es tomar las categorías como iluminadoras y no como reflejos, intentando con ello abrir nuevas lecturas sobre el proceso de dependencia del caso uruguayo. La corporación internacional se ubica en los centros de poder económico, en los países hegemónicos, y cuenta con sucursales en los países periféricos donde es posible producir de modo redituable. En el país o casa central los vínculos pueden ser privados o asentarse sobre convenios privado - públicos pero siempre mantienen un vínculo con el Estado porque su poder, aunque supera los límites estatales, se sirve del mismo y se extiende al campo político. La influencia de sus representantes en la escena política hace que los países centrales defiendan -legislativa y económicamente a nivel internacional- sus intereses y que carezcan de autonomía para contradecir los mismos. En este sentido, los países centrales mantienen también grados de dependencia con estas grandes firmas. Estas corporaciones si bien guardan una base nacional en términos del destino de las ganancias y de la división de intereses entre los países centrales y los periféricos, pueden tener raigambre en múltiples países y aún ser "anacionales", asentando toda su estructura en una coalición de empresarios de múltiples nacionalidades y la compra de acciones mediante sociedades anónimas. Kaplan sostiene que la corporación internacional

"Puede actuar eficazmente sobre variables fundamentales de la economía, de la sociedad y del sistema político de la razón de origen, facilitar o contrariar las políticas económicas y las acciones diplomáticas, crear graves desequilibrios internos e internacionales." (KAPLAN, 1972: 64)

En términos de su campo de acción estas corporaciones operan a escala global, utilizando las regiones y los países acorde a los cambios en las variables mundiales tanto a nivel económico como político. De tal forma que las transformaciones nacionales periféricas son tenidas en cuenta como variables de presencia o ausencia en los mercados locales, y no como un escenario determinante para la empresa. De esta manera se comporta como una "macrounidad", con una base de 
decisión centralizada. El carácter mundial de su empresa lo vuelve autónoma frente a las estructuras de gestión, administración y aún económicas locales, las fronteras nacionales carecen de sentido para la construcción de su rentabilidad o pérdida como macrounidad, y construye su propia estructura y su propia balanza comercial.

En los países periféricos las particularidades son o bien fuente de ventajas y especialización, o bien rechazadas radicalmente y reducidas a su mínima expresión, generando una clara tendencia a la homogenización de los procesos y sucursales. En la periferia la incidencia de estas corporaciones sobre el poder político es trascendente, cooptando el mismo y/o forzando a este a ceder posiciones e intereses.

"Frecuentemente domina los poderes públicos de las naciones en que se instala, los cuales, en el mejor de los casos se ven obligados a negociar con ella en la oscuridad. Las transacciones internacionales de la corporación mezclan aspectos de derecho público y de derecho privado, y a veces constituyen tratados disfrazados (Iranian Oil Agreement, 1954). Los caracteres y resultados de sus acciones generan frecuentemente diversas tensiones y conflictos dentro de los países, entre estos, entre regiones y entre bloques." (KAPLAN, 1972: 66).

Consecuentemente, continúa Kaplan, los intereses de estas corporaciones se ubican fuera del espacio latinoamericano y combinan su búsqueda de expansión comercial con la pretensión de poder y control, de modo que los intereses nacionales pueden estar en conflicto y aún ser contrariados por estos actores económicos supra estatales.

En Uruguay, la presencia más evidente del ingreso de transnacionales en el agro se dio de la mano de la expansión de las forestales en el país. Estas empresas se ubicaron dentro del país facilitadas por la Ley de Promoción Forestal (Ley 15.939) que supuso una serie de subsidios para el desarrollo de la producción forestal en zonas consideradas de prioridad para esta producción. La mencionada ley no tuvo aspectos discriminatorios en términos de la nacionalidad de los productores, habilitando un desarrollo nacional y foráneo. De esta forma los primeros años, y montes, de producción forestal con destino industrial tuvieron una alta presencia nacional, ubicándose a finales de los años '90 un proceso de extranjerización de las plantaciones que contaba a Weyerhaeuser, FOSA - BOTNIA y ENCE como las principales protagonistas. Un aliciente en este proceso lo constituyó la Ley 16.906 o Ley de Inversiones que prioriza los proyectos de inversión sin distinción en torno a la nacionalidad y habilita a inversores extranjeros a ubicarse en Uruguay de la mano de importantes estímulos fiscales. De esta forma, las empresas extranjeras compraron los montes nacionales y desarrollaron nuevos montes de la mano de importantes alivios fiscales que el país orientó a la producción forestal y a la inversión, siendo por ende empresas transnacionales subsidiadas por el Estado uruguayo. Alvarado 
(2009) identifica que el modelo de expansión de la producción forestal en el mundo se desarrolla en dos etapas, una de ubicación de nuevos bosques remitentes a las industrias nórdicas, y una segunda etapa de localización de las industrias más agresivas con el ambiente en los propios países periféricos, estimulada por las presiones de los movimientos ecologistas centrales. Florit (2012) analiza el carácter encadenado de las inversiones vinculadas a la forestación en el Uruguay, identificando un proceso por el cual la primera inversión en montes ha servido para la construcción de una retórica de lo necesario o inevitable, empujando al país en nuevas inversiones al servicio de la cadena forestal celulósica, especialmente nuevas plantas de celulosa, más zonas francas y el dragado y generación de puertos aguas profundas. Esta expansión ha supuesto para el país la presencia en múltiples conflictos internos y regionales, de modo que el conflicto ambiental que afrontaran los países nórdicos se ha trasladado a la periferia donde el desarrollo y fortaleza de los movimientos ambientales es menor.

Un segundo impulso extranjerizador llegó al país de la mano de la crisis económica del año 2002 y del contexto de la crisis alimentaria mundial. Mientras el escenario rural del país se transformaba a partir de la instauración de los bosques de eucaliptus y pinos, Uruguay recibió nuevos visitantes, capitales financieros que se trasladaron al agro en busca de tierras con destino de cultivos agrícolas. Como se señaló, históricamente la agricultura del país fue muy débil dedicando pocas hectáreas al cultivo de cereales principalmente trigo con destino a molinos, y sorgo o cultivos forrajeros como complemento para la alimentación animal. En ese escenario la llegada de capitales con destino a los cultivos de trigo y soja transgénicos revolucionaron el rubro agrícola y el agropecuario en general. La demanda de tierras fue contundente tanto en cuantía como en tiempo y sumado esto a la demanda de tierras con fines forestales, la renta de la tierra se multiplicó obteniendo impactos diversos en la estructura agraria del país. En el año 2000 se transaron unas 308.000 hectáreas a un precio promedio de US\$ 448 mientras que en 2012 se transaron 371.000 a un precio promedio de US\$ 3.519.

La sojización trajo consigo la agriculturización del agro, proceso que el Uruguay lo veía de costado en sus vecinos: Argentina y Brasil. Entendemos aquí por agriculturización no a la primacía de la producción agrícola sobre otros rubros (sentido dado por algunos colegas en Argentina) sino al proceso de expansión de la lógica empresarial característica de la agricultura y del agronegocio a todo el sector agropecuario.

La profundización de la actividad agrícola extensiva supuso la profundización de la comercialización de insumos y maquinaria, cuestiones que hasta el momento en Uruguay eran muy reducidas. En el 
año 2005 el país importó unos US $\$ 49$ millones en maquinarias, piezas e instrumentos vinculados al sector agrícola mientras que en 2011 la cifra fue de US\$ 255 millones, principalmente tractores y máquinas cosechadoras. En el Uruguay se fabrican accesorios para maquinaria agrícola pero no maquinas motorizadas y en ese sentido el proceso de sojización resulta ser altamente dependiente de insumos y maquinarias producidos en el exterior. 5 Dentro de las 10 principales importaciones del país se encuentra la maquinaria agrícola, abonos químicos y nitrogenados y plaguicidas. (URUGUAY XXI, 2013)

La comercialización de estos productos es también dependiente del exterior. El modelo agroexportador implica una alta dependencia del mercado internacional y de las condiciones que éste establece. En los últimos 5 o 6 años las condiciones han sido favorables para el país en cuanto a los precios de sus principales productos de exportación: carne, granos y madera. Si bien la proporción de la soja es menor, esta también se exporta en su mayoría tanto en grano como en semillas. La exportación del grano de soja tiene como principal destino China (74\%), Egipto (9\%) y México (3\%). (URUGUAY XXI b, 2014: 4)

Tabla 1. Principales productos exportados en millones US\$

\begin{tabular}{|l|c|c|c|c|}
\hline \multicolumn{1}{|c|}{ Producto } & $\mathbf{2 0 1 1}$ & $\mathbf{2 0 1 2}$ & $\mathbf{2 0 1 3}$ & $\mathbf{2 0 1 4}$ \\
\hline Semillas y frutos oleaginosos & 865 & 1.403 & 1.877 & 1.626 \\
\hline Carne y despojos comestibles. & 1.475 & 1.577 & 1.487 & 1.706 \\
\hline Cereales & 817 & 1.056 & 914 & 845 \\
\hline Leche y productos lácteos & 737 & 790 & 923 & 836 \\
\hline $\begin{array}{l}\text { Madera, carbón vegetal y } \\
\text { manufacturas de madera }\end{array}$ & 523 & 469 & 560 & 685 \\
\hline
\end{tabular}

Fuente: Uruguay XXI (2014)

Los principales destinos de exportación del país siguen siendo Brasil, Argentina y las Zonas Francas.En los últimos años la Zona Franca de Nueva Palmira se ha mantenido dentro de los principales destinos principalmente por ser el mercado intermediario de la soja, el trigo y la pasta de celulosa. Durante el 2014 los principales destinos fueron Brasil $(18,1 \%)$, China $(16,7 \%)$ y la Zona Franca de Nueva Palmira (7\%).

\footnotetext{
5 El Uruguay produce algunos insumos tales como biocidas y semillas, sin embargo gran parte de la producción depende de importaciones de estos productos. En promedio el país importa un $37 \%$ de la semilla de soja utilizada en los cultivos lo que equivale a unas 20.000 toneladas. (INASE, 2010)
} 
El contexto señalado da cuenta de que el modelo agroexportador se mantiene profundizando la exportación de commodities, la dependencia de los mercados internacionales y la continuidad en ser un país tomador de precios, la extranjerización de la matriz productiva del país: extranjerización de la tierra, llegada de bancos extranjeros, llegada de filiales de transnacionales de los agronegocios (de maquinarias, de celulosa, de soja, de insumos) y por tanto una cadena global de valor altamente dependiente desde el insumo hasta la comercialización. El sector agropecuario se ha visto en un proceso de profundización del agronegocio, de la fusión de capitales financieros con capitales agropecuarios, de capitales industriales con capitales financieros, de una fuerte presencia de empresas transnacionales que marcan la tendencia del sector agropecuario nacional y que poco tienen que ver con la tradicional lógica agropecuaria del país.

"Así, la presencia multinacional parece tener un efecto de desplazamiento ("crowding out") sobre las empresas domésticas, reduciendo así su productividad. Sin embargo, hay evidencia de efectos positivos a través de encadenamientos hacia atrás ${ }^{6}$ con firmas domésticas." (PELUFFO, 2011:29)

De esta forma y como lo muestra la Tabla II, el país pierde su capacidad de ser protagonista en la producción nacional, cediendo los principales ámbitos de exportación a empresas extranjeras que se ubican como punteras sectoriales y que realizan procesos de concentración de capitales mediante la compra de empresas menores.

Tabla 2. Principales empresas exportadoras 2011-2013

\begin{tabular}{|l|l|}
\hline \multicolumn{2}{|c|}{ Año 2013} \\
\hline $\begin{array}{l}\text { CONAPROLE: COOPERATIVA } \\
\text { LECHE }\end{array}$ & Uruguay DE PRODUCTORES DE \\
\hline CROP URUGUAY S.A. & $\begin{array}{l}\text { Cargill International y Hiper Insumos S.A. } \\
\text { En la actualidad son importantes } \\
\text { exportadores de soja, trigo y girasol. }\end{array}$ \\
\hline S.A.M.A.N. & CAMIL Alimentos S.A Brasil \\
\hline BARRACA JORGE W ERRO S.A. & $\begin{array}{l}\text { Uruguay, exportación de granos y } \\
\text { oleaginosas }\end{array}$ \\
\hline $\begin{array}{l}\text { COMPAÑIA FORESTAL ORIENTAL } \\
\text { S.A. }\end{array}$ & $\begin{array}{l}\text { Perteneciente a UPM, capitales } \\
\text { Finlandeses, exportación de madera }\end{array}$ \\
\hline
\end{tabular}

6 El encadenamiento hacia atrás refiere a que las empresas transnacionales incorporan a empresas domésticas en su cadena de valor, por ejemplo a través de la tercerización de servicios; no obstante desplazan a sus competidores generando un efecto de concentración de capital y marcando tendencias oligopólicas hacia el mercado. 


\begin{tabular}{|c|c|}
\hline LDC URUGUAY S.A. & $\begin{array}{l}\text { Louis Dreyfus Commodities } \\
\text { Transnacional con sede en Francia }\end{array}$ \\
\hline CEREOIL URUGUAY S.A & Uruguay, productos oleaginosos \\
\hline GARMET S.A. & Uruguay, agroquímicos \\
\hline FRIGORIFICO TACUAREMBO S.A. & MAFRIG Global Foods Brasil \\
\hline $\begin{array}{l}\text { ESTABLECIMIENTOS COLONIA } \\
\text { S.A. }\end{array}$ & MAFRIG Global Foods Brasil \\
\hline \multicolumn{2}{|r|}{ Año 2011} \\
\hline Empresa. & Origen del capital. \\
\hline GLADENUR S.A. & Jordania. \\
\hline $\begin{array}{l}\text { AARHUSKARLSHAMN LATIN } \\
\text { AMERICA S.A. }\end{array}$ & $\begin{array}{l}\text { Empresa original de Dinamarca, con } \\
\text { posterior inclusión de USA, Suecia, } \\
\text { México y Reino Unido }\end{array}$ \\
\hline MALTERÍA URUGUAY S.A. & $\begin{array}{l}\text { M.U.S.A. pertenece a Maltería Pampa } \\
\text { (Argetina) y esta a su vez pertenece a } \\
\text { AMBEP (Brahma, Brasil) }\end{array}$ \\
\hline LANAS TRINIDAD S.A. & $\begin{array}{l}\text { Francia. Pertenece a Chageurs, líder } \\
\text { mundial en producción de tops. }\end{array}$ \\
\hline FRIGORÍFICO CANELONES & Brasil. Grupo Bertin. \\
\hline BARRACA JORGE W. ERRO S.A. & $\begin{array}{l}\text { Uruguay. Mantiene convenio con } \\
\text { Archer D. Midland (USA) y es } \\
\text { representante de MONSANTO en } \\
\text { Uruguay. }\end{array}$ \\
\hline $\begin{array}{l}\text { S.A. MOLINOS ARROCEROS } \\
\text { NACIONALES (SAMAN) }\end{array}$ & Brasil. Pertenece a Camil Alimentos S.A. \\
\hline CITRÍCOLA SALTEÑA S.A. & $\begin{array}{l}67 \% \text { en manos de la familia Caputto } \\
\text { (Uruguay) y } 33 \% \text { en manos de la } \\
\text { empresa San Miguel (Argentina) }\end{array}$ \\
\hline $\begin{array}{l}\text { COMPAÑÍA FORESTAL ORIENTAL } \\
\text { S.A. }\end{array}$ & $\begin{array}{l}\text { Pertenece a UPM. UPM es una } \\
\text { multinacional con plantas en } 16 \text { países } \\
\text { en las que emplea } 22.000 \text { personas. } \\
\text { Opera en la bolsa de valores de } \\
\text { Helsinki. }\end{array}$ \\
\hline PAYCUEROS S.A. & $\begin{array}{l}\text { SADESA. Multinacional cita en } 18 \\
\text { países en } 5 \text { continentes. }\end{array}$ \\
\hline CO.NA.PRO.LE. & Uruguay. Cooperativa. \\
\hline
\end{tabular}


Fuente: Información de Ppales. Exportaciones Uruguay S.XXI. Sitio web oficial: uruguayxxi.gub.uy Información del origen de capitales elaboración propia a partir de sitios web de las empresas y comunicaciones públicas de las empresas.

Asimismo, y de la mano de esta importante transnacionalización de la producción agropecuaria, el país ha visto removida su estructura agraria, creciendo en concentración de la tierra a la par que viendo intensificado el uso de los suelos. Estos cambios en el mercado de tierras, han sido paradigmáticos en el país en tanto la envergadura del fenómeno se ha acompañado de una inmovilidad de parte del gobierno en particular y del Estado en general de responder al embate extranjerizador. Lejos de la soberanía legislativa, el país a través de sus representantes políticos ha manifestado sistemáticamente su preocupación por las condiciones del mercado de tierras sin poder concretar una ley que limite el fenómeno luego de varios intentos legislativos fallidos. La versión más elocuente de ello puede encontrarse en el Impuesto a la Concentración de los Inmuebles Rurales (ICIR) que surgió como respuesta a las demandas sociales frente al proceso de concentración y extranjerización de la tierra, se aprobó como un impuesto a la propiedad de la concentración -no arrendamientos- y finalmente se derogó al año de implementación.

La aprobación del ICIR generó la respuesta inmediata de la clase terrateniente del país representadas dignamente por la Asociación Rural del Uruguay y la Federación Rural del Uruguay. Estas instituciones trabajaron duramente para llegar a la conclusión de que el impuesto era inconstitucional debido a que generaba un impuesto nuevo a nivel departamental lo cual contradice la Constitución de la República. Capítulo aparte vivió el gobierno uruguayo en sus negociaciones con las transnacionales UPM y Montes del Plata. A través de acuerdos macro establecidos en leyes con algunos países centrales y con el régimen actual de promoción de inversiones, el gobierno de Uruguay firma contratos con estas dos empresas en las cuales se compromete a no modificar el sistema tributario en perjuicio de las mismas. En este contexto la generación del ICIR que aplica a quienes tuvieran más de 2000 hectáreas atentaba directamente contra las empresas forestales. En particular la negociación con Montes del Plata cobró público conocimiento obligando al Estado uruguayo a admitir que la empresa abonaría el ICIR puesto que el mismo no implicaba una reducción en su rentabilidad; ; en caso de afectar la rentabilidad de la empresa la misma podría solicitar una exoneración. Casualmente, el ICIR comenzaría a recaudarse en noviembre de 2012 y en octubre del

\footnotetext{
7 http://www.presidencia.gub.uy/comunicacion/comunicacionnoticias/frugoni-radiouruguay-icir-nota
} 
mismo año el Poder Ejecutivo aprueba la solicitud de Montes del Plata (y sus empresas afiliadas que son 8) a la exoneración total del Impuesto al Patrimonio. 8

Otro ejemplo en consonancia fue la derogación al mes de su aprobación del artículo de la reforma del Instituto Nacional de Colonización (INC) que permitía a este la compra de una fracción de los campos de más de 1000 há. Actualmente el INC puede comprar campos indivisos y no fracciones del mismo. La compra fraccionadA de predios es un recurso colonizador al tiempo que permite una reforma agraria convencional, sin embargo las presiones políticas y corporativas llevaron a que el INC se mantenga con su régimen actual.

El resultado, ante estos intentos, ha sido que al año 2011 el Censo Agropecuario evidencia la desaparición de 12.000 de las 57.131 explotaciones existentes en el año 2000, 11.000 de las cuales eran explotaciones que gestionaban hasta 99 hás. Asimismo, el censo evidencia que un $9 \%$ de las explotaciones maneja el $60 \%$ de la superficie del país, que un $3 \%$ de la tierra uruguaya está en manos de extranjeros y un $43,1 \%$ está bajo la forma de explotaciones que no son personas físicas y por tanto con nacionalidad no identificables. (DIEA, 2013).

\section{iv.ii. Especialización deformante}

La expansión de las corporaciones transnacionales en América Latina ha supuesto una modificación del modelo colonialista de extracción de materias primas y venta de manufacturas por un modelo de inversión directa en los propios países periféricos. Habida cuenta de un proceso estimulado e intervenido estatalmente de desarrollo de las industrias locales, el modelo debió ser revisado y llevó a una pauta de inversión donde los países centrales desarrollan industrias sobre la base de primarias inversiones nacionales. De esta forma la inversión extranjera viabiliza el control y la determinación del mercado latinoamericano desde dentro de los propios países, desarrollando únicamente aquellas industrias, regiones y ramas funcionales a la centralización y acumulación de capital desde el centro. De esa forma el acceso al mercado interno es mayor y es posible desarrollar un centro de demandas de técnicos, maquinaria y tecnología desde las sucursales a las casas matrices. Esto cuenta con las concepción positiva de las inversiones extranjeras que existen en los países periféricos que, en aras de captar el financiamiento foráneo, estos generan condiciones impositivas, fiscales y de regulación comercial y laboral más flexibles y menos exigentes que las de los países centrales.

\footnotetext{
8 Resolución del Ministerio de Economía y Finanzas del 22 de octubre de 2012.
} 
La inversión en ciertas ramas y sectores de las economías latinoamericanas supone el estímulo desigual y el desarrollo diferencial entre ramas y subsectores, de este modo las economías locales no logran generar desarrollos integrados y aunados. Esta fragmentación de las economías locales supone la existencia de sectores desarrollados, erigidos en función de las demandas exógenas, y amplios sectores de la economía atrasados orientados a las necesidades de las poblaciones latinoamericanas y ajustadas a las posibilidades de consumo de sus trabajadores sobre explotados. Parte del escenario de inserción de los países latinoamericanos en el mercado mundial, y en particular en el mercado de commodities, está signado por un lugar subordinado en las condiciones de intercambio, según las cuales estos países aparecen como tomadores de precios, con economías domésticas fuertemente limitadas por las oportunidades comerciales externas y por los intermediarios (GUDYNAS, 2009). De modo que el escenario de incremento de precios puede concebirse como un modelo que condiciona la producción nacional y refuerza la dependencia del país frente al mercado mundial y la demanda externa. Esta situación profundiza un modelo donde los países latinoamericanos se ubican en las cadenas productivas como proveedores de materias primas. En ese marco el Uruguay se ubica como un país agroexportador, pero se ha mantenido como exportador concentrado con escasa diversidad productiva (Instituto URUGUAY XXI, 2011)9. En particular, el escenario actual muestra un país que mantiene una balanza comercial deficitaria pese a la situación de demanda mundial de materias primas y los alimentos, y que carece de condición para una rápida conversión productiva así como de capacidad de negociación comercial ante la variabilidad de precios de los commodities.

Concretamente el Instituto Uruguay XXI (2011) diagnostica un leve incremento de los destinos de exportación -con una mejora relativa intermedia en relación a los países competidores- pero que se acompaña de un proceso de concentración de los bienes de exportación, destacándose una retracción en los productos con mayor industrialización a favor de la importancia mayor de los productos primarios.

\footnotetext{
9 Conviene señalar a su vez que la Soja, producto de gran peso en las exportaciones y principal responsable del crecimiento sectorial, está fuertemente concentrado en términos de destino, por lo tanto existe una importante dependencia del Uruguay como de los restantes países exportadores de soja- de los reducidos mercados que demandan este producto. (Instituto Uruguay XXI. Documento de trabajo No3. Departamento de Inteligencia Competitiva. Mdeo, 2011.)
} 


\section{Gráfico I. Concentración de exportaciones por producto1990 - 2012. (En porcentaje)}



Fuente: Ministerio de Economía y Finanzas, 2013.

Un ámbito central en la polémica en torno al modelo instaurado en el agro se relaciona con el uso de los recursos naturales. Concretamente se identifica un proceso de desarrollo basado en un modelo de división mundial del trabajo. Este ubica a los países como Uruguay en un rol de países "exportadores - extractores", mientras los países "importadores elaboradores" incorporan valor a los productos asumiendo las fases más desarrolladas de las cadenas de valor agroindustrial. Como deja ver el Grafico I, algo más del $80 \%$ de las exportaciones del país tienen como base la explotación de recursos naturales con baja elaboración.

Esta situación ha dado comienzo hace aproximadamente 30 años y se ha agudizado con el establecimiento de un esquema mundial de distribución de roles de los diversos países ${ }^{10}$, donde la base de disposición de recursos naturales y humanos juego un papel importante. De esta forma los países asiáticos aparecen como países con una gran población y con una reducida disponibilidad de recursos naturales (RRNN), mientras los países de América Latina, y el Uruguay especialmente, aparecen como países con una alta relación RRNN/población. ${ }^{11}$ Esta situación dispone a unos y otros países en

\footnotetext{
10 Se resaltan las investigaciones destinadas a mostrar las consecuencias negativas que tuvo para las economías latinoamericanas manufactureras la incorporación de China al mercado mundial, y las consecuencias positivas en términos de exportación para aquellas economías abocadas a la producción de commodities. (Al respecto véase FMI (2004); Ianchovichina y Martín (2006); Lehmann, Moreno y Jaramillo (2007))

11 Recientemente el Ministro de Ganadería, Agricultura y Pesca del Uruguay comentó que el país produjo alimentos para 28 millones de consumidores y que tiene las capacidades de producir para 50 millones. http://www.mgap.gub.uy/portal/afiledownload.aspx?2,1,12,0,S,0,9837\%3bS\%3b1\%3b2 O,
} 
condiciones relativas disímiles a la hora de lograr ventajas comparativas en los mercados mundiales, estimulando con ello el desarrollo de industrias manufactureras intensivas en trabajo en los países del primer grupo, y producciones intensivas en RRNN en los países del segundo grupo (Paolino, 2010).

Una de las principales características de esta dimensión de las corporaciones transnacionales es, como se señaló, que las empresas delinean una estrategia de mercado en la cual seleccionan sus lugares de producción en torno a determinadas variables: disponibilidad, calificación y costo de la mano de obra, acceso a insumos, políticas fiscales, capacidades y logísticas y de comercialización. Muchas de estas características pueden promoverse y generarse con el impulso y apoyo de las mismas corporaciones. Luego de generadas estas condiciones el país anfitrión puede colocarse como un cluster sectorial en el cual cualquier empresa del rubro puede acceder a los mismos beneficios. El caso uruguayo camina en ese sentido: en el caso de la forestación, inicialmente Uruguay no tenía bosques por lo que hubo que promover su cultivo con beneficios fiscales, posteriormente se negociaron condiciones para la instalación de la primera planta procesadora (Botnia) la cual se enfrentó a la escasez de mano de obra calificada ${ }^{2}$ para su construcción. Luego de este primer emprendimiento la segunda transnacional forestal (Montes del Plata) ingresó al país con mejores condiciones, con bosques ya plantados, con mano de obra con experiencia en construcción de plantas industriales, con mecanismos fiscales ya establecidos, entre otros. Actualmente el país negocia la instalación de una tercera planta que implicará una inversión aún mayor que la de Montes del Plata (la mayor en la historia del país).

Este contexto ubica al país como un territorio especializado en la forestación lo cual favorece la instalación de nuevas empresas vinculadas al rubro pero que al mismo tiempo requiere de estrategias de negociación y medidas políticas que defiendan el sector en detrimento de otros sectores productivos.

\section{iv.iii. Descapitalización}

La tesis marxista de la centralización del capital orienta a mostrar que el proceso de inversión de capital extranjero reproduce el mecanismo de

\footnotetext{
12 Hubieron algunos conflictos entre sindicatos y gobierno por esta dificultad. La primera medida para solucionar el problema fue la incorporación de trabajadores nórdicos lo cual generó el descontento de los trabajadores uruguayos. Esta medida se mantuvo a su vez en la fase agraria de la producción aunque en menor medida. Montes del Plata, si bien contó con mayores ventajas en la disponibilidad de la mano de obra local también recurrió a la mano de obra extranjera para la construcción de la planta.
} 
la dependencia al permitir una fuga de divisas del país que "descapitaliza" su economía y lo hace dependiente de los préstamos externos. Este proceso de descapitalización se soporta en primer lugar bajo el estímulo a la importación de recursos materiales y tecnológicos del centro, haciendo del proceso de inversión un proceso de repatriación de la inversión mediante el consumo de técnicos asesores, maquinaria, patentes, entre otros. A este proceso se adiciona que las inversiones extranjeras utilizan en su proceso de inversión de recursos financieros, préstamos y estímulos fiscales subvencionados por los propios países receptores de la inversión.

Estas inversiones conviven con endeudamiento de los países receptores que no logran revertir el déficit de sus balanzas de pago y soportan sus economías y decisiones políticas y programáticas sobre los préstamos internacionales. Este endeudamiento ha sido frecuentemente catalogado como de endeudamiento político, ya que los préstamos suponen planes de acción y estrategias de desarrollo a las cuales los países se comprometen viendo condicionadas las orientaciones nacionales.

En Uruguay la deuda pública fue desde los inicios del Estado nacional la estrategia de supervivencia de los gobiernos, de modo que ya en 1828 el débil Estado uruguayo se endeudaba para mantenerse y fortalecerse, aunque hasta 1880 los principales acreedores del Estado eran prestamistas privados nacionales y regionales (BERTINO Y BERTONI, 2004). A finales del siglo XIX se instalaba la deuda pública en el exterior, y aunque con variaciones, este camino pasaría a hacer un importante referente para el financiamiento del Estado uruguayo. De esta forma, el país arribaría a 2002 con una deuda externa de 11.000 millones de dólares, deuda que a pesar de la crisis social y económica que azotaba al país no se incumplió (como sucedió en la tablita) sino que se re negoció y se manejó mediante canjes y reestructuras que dispararon el nivel de endeudamiento (BERTINO Y BERTONI, 2004). 


\section{Gráfico II. Evolución de la Deuda Externa Bruta del Uruguay}

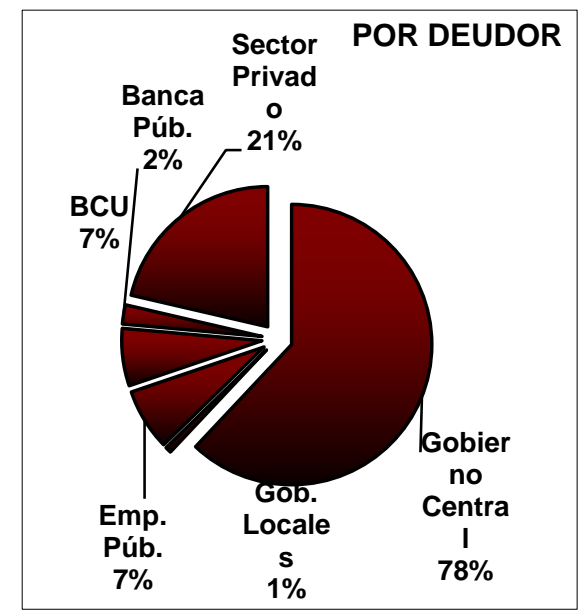

Fuente: Banco Central del Uruguay. Setiembre 2014.

En la actualidad la política de gobierno se ha orientado a la retracción de la deuda externa, buscando reducir el peso de la misma sobre el PBI nacional. Para esta retracción se han dado dos procesos paralelos, por una parte un crecimiento del PBI de la mano de la extranjerización de ciertas producciones que resulta útil a la relación deuda - PBI, de modo que el país se ha abocado a la captación de inversión extranjera y generado instituciones expresamente destinadas a ello (COMAPA, Uruguay XXI). Por otra parte, un proceso de conversión de la deuda orientada a la comercialización de la misma entre empresarios privados en lugar de entre agentes financieros internacionales (VERGER, 2003). En este sentido, si bien la orientación de la deuda pública se distancia de la descripción hecha por Kaplan la dependencia de la economía nacional de la inversión extranjera se ha dinamizado de forma que los compromisos del país con el mercado internacional y con las empresas transnacionales replican en una esfera diferente las relaciones condicionadas y dependientes entre el país y el exterior. Ejemplos de ello son los acuerdos GATT -ronda de comercio-, la ya mencionada Ley de promoción de inversiones, el acuerdo marco fijado con el Nordic Investment Bank y una treintena de acuerdos bilaterales de inversión (FLORIT Y PIEDRACUEVA, 2012). ${ }^{13}$

\section{iv.iv. Subordinación colonial}

13 Al tiempo que el Estado uruguayo promueve la agricultura y la forestación por medio de subsidios y exoneraciones fiscales se endeuda con el Banco Mundial en un proyecto que incluye la puesta en práctica del Plan de Uso y Manejo de Suelos, medida tomada por la previsión de las consecuencias que generará la agricultura en los suelos del país. 
La subordinación colonial surge como producto de la naturaleza de las corporaciones trasnacionales ya que lleva a que la inversión extranjera represente un alto porcentaje de la inversión total en los países latinoamericanos. Esta inversión se ubica en puntos clave de las economías, constituyendo frecuentemente monopolios o ubicándose en las fases estratégicas y determinantes de los enclaves y las cadenas productivas. Estas inversiones se orientan frecuentemente hacia el control de las ramas y sectores, ubicándose preferencialmente por el manejo de las cadenas más integradas. De ese modo, las corporaciones se ven reforzadas por su integración al mercado mundial que permite ventajas comparativas para la colocación de la producción, así como por la disposición de mayor tecnología y capital. A nivel nacional se vinculan con sectores capitalistas nacionales integrándolos a paquetes accionarios o como subalternos de las cadenas de producción. Finalmente estas corporaciones logran frecuentemente políticas favorables a su inversión que aseguran condiciones de rentabilidad superiores a las de los capitalistas nacionales.

En este punto la tecnología tiene un lugar clave. Las corporaciones internacionales son frecuentemente centros de investigación que desarrollan y propagan sus producciones tecnológicas. Sin embargo Kaplan (1972) señala que estas tecnologías son en multiplicidad de casos desajustadas para los niveles de desarrollo latinoamericanas y que no se integran a las economías locales sino que suponen incorporaciones de gran valor, excesivas en las relaciones capital/trabajo de las relaciones de producción periféricas, siendo usualmente incorporaciones que suponen la sustitución de trabajadores y el incremento del desempleo.

Como modelo organizativo las corporaciones expanden los productos de su innovación tecnológica en la medida que pueden obtener regalías por ellos y/o que los mismos son necesarios para el desarrollo de empresas redituables por parte de las filiales en la periferia. Sin embargo esta expansión tecnológica no supone el estímulo al desarrollo de investigación autónoma en los países dependientes ni la investigación científica como función de las filiales, sino que la investigación y el manejo de esa información son privativos de los ámbitos centrales.

Como se señaló al analizar la especialización deformante, las transnacionales del agronegocio en Uruguay cuentan con una lógica de funcionamiento vertical. Esto es que la cadena productiva se encuentra centralizada en la empresa o a través de convenios yacuerdos entre empresas transnacionales. El complejo agroforestal del país es un ejemplo certero de este proceso. UPM, la empresa madre del proceso en el país, cuenta con una empresa nacionalizada (UPM Forestal Oriental S.A) que es su agente forestal. Esta empresa tiene a su cargo el proceso de vivero, de plantación y cuidado, cosecha y 
transporte de la producción. Si bien terceriza algunos servicios, y por tanto genera un encadenamiento hacia atrás tal como señalara Peluffo (2011) en referencia a las IED, la cadena se encuentra centralizada en la empresa UPM.

El complejo sojero muestra características diferentes; hasta hace poco tiempo la empresa más grande en el país era la transnacional El Tejar (hoy Union Agriculture Group) quien se encargaba principalmente de la etapa agraria del proceso puesto que en el país la fase industrializadora es casi inexistente. Sin embargo, y dentro de la lógica del agronegocio, UAG forma parte del Lobby agrícola mundial junto con empresas como Monsanto, Syngenta, Basf, John Deere, CAT, etc. De esta manera la cadena productiva cuenta con agentes que están vinculados a nivel internacional y que logran a cuerdos sobre el modo de producción en las distintas partes del mundo. Estas cuestiones logran una manifestación en el país a través de los contratos de medianería en los que UAG ofrece al productor la maquinaria, los insumos y la Asistencia Técnica quedando como responsabilidad del productor disponer de la tierra. Estos paquetes Asistencia-maquinaria-insumos dan cuenta de un proceso de encadenamiento en un modelo de mercado oligopólico altamente concentrado.

Estas características permiten a las corporaciones transnacionales influir directamente en las decisiones políticas del país. La dependencia de los capitales externos y el carácter oligopólico y monopólico de algunos sectores, habilitan un poder de negociación extremo de las empresas para con el Estado. En los últimos años el país se ha visto inmerso en diversas situaciones de esta índole. Ya ha sido señalado el conflicto que mantuvo el Estado uruguayo con el ICIR, en particular interesa en este apartado la negociación mantenida con Montes del Plata en el contexto del acuerdo firmado entre Uruguay y el Nordic Investment Bank de Finlandia. Otro ejemplo es el requerimiento de zona franca de Montes del Plata y UPM para realizar su inversión en el país; ambas empresas estaban dispuestas a invertir en Uruguay bajo el régimen de Zona Franca, incluso Botnia en su momento negoció paralelamente con el gobierno Argentino y ante la negativa de este de ampararlo en los beneficios fiscales optaron por su instalación en Uruguay.

Con fecha de 18 de enero de 2011 el Estado Uruguayo firma el contrato de Inversión con Montes del Plata. El contrato se mantuvo en forma confidencial hasta el 16 de junio del mismo año. La confidencialidad estaba resguardad en un artículo del contrato en el que las partes se comprometían a no brindar ni parcial ni totalmente información sobre el contrato. La confidencialidad cae luego de una intimación judicial realizada por un fiscal y luego de varias negociaciones políticas. En concreto, el contrato firmado por las partes establece y deja en claro una serie de beneficios y compromisos del Estado uruguayo que pueden ser considerados al menos atípicos. Bajo el argumento de que 
el proyecto de inversión es considerado de Interés Estatal, Montes del Plata solicita al Estado uruguayo: aprobación inmediata del proyecto de inversión de la plata, la expropiación de tierras para la ampliación de rutas, el dragado del canal Martín García sobre el Río Uruguay, el permiso para contratar mano de obra extranjera que supera los límites permitidos por la Ley de Zonas Francas, el mantenimiento óptimo de las rutas nacionales que llegan a la planta, la aprobación de proyectos forestales en un radio de 200 kilómetros de la planta aún cuando no sean considerados de aptitud forestal, la negación del derecho del Instituto Nacional de Colonización de ejercer la opción de compra en las transacciones de fusión de empresas que realizará Montes del Plata, ${ }^{14}$ la exoneración de impuestos a la fusión de Montes del Plata con otros empresas, a la habilitación de extender la capacidad de producción de la planta o a extender el espacio de la zona Franca; a su vez se acuerda que el proyecto está amparado en los acuerdos marco firmados entre Uruguay y Chile (por Arauco) y entre Uruguay y Finlandia (por Stora-Enso) ${ }^{15}$ y también explicitan que cualquier discordancia sobre lo pactado será resuelto por tribunales internacionales, tal como si se firmara un acuerdo entre Estados nacionales.

Estas y otras condicionantes dan cuenta del poder de las corporaciones transnacionales frente a los estados dependientes de nuestra Latinoamérica. La clase política de los países periféricos se enfrenta al desafío de generar determinado bienestar en la sociedad intentando alejarse de las medidas políticas conocidas durante el período neoliberal lo suficientemente estigmatizadas, al menos en el Cono Sur de América Latina. Ya a finales de la década del ' 60 del siglo pasado varios dependentistas acordaban en el necesario giro de las clases políticas frente a las transformaciones de la economía mundial y del avance del capitalismo (BORON, BAMBIRRA, QUIJANO, y otros, 1968) El siglo XXI trae a los países periféricos nuevas modalidades de avance del capitalismo, nuevas estrategias, nuevas expectativas en la población local y quizás, las mismas capacidades. La subordinación colonial es, en este sentido, una categoría clara que permite comprender los procesos analizados y proyectar algunos posibles escenarios futuros para el país.

\section{Conclusiones. La espada de Damocles}

Cuando en enero de 1850, Melchor Pacheco y Obes, enviado extraordinario del gobierno de Montevideo, reprochó al Ministro de Relaciones Exteriores de la República Francesa la conducta de su cónsul, con el argumento de que "... en Francia los hombres más

\footnotetext{
14 El INC tiene prioridad de compra en aquellos predios superiores a las 500 hectáreas. Esto es que, al momento de vender un predio de esas dimensiones, el INC puede optar por comprarlo con prioridad frente a cualquier otro comprador.

15 Montes del Plata es un Joint Vneture entre estas dos empresas.
} 
eminentes no tenían la pretensión de ser inviolables para la prensa..." tuvo que oír un legítimo argumento del orgullo europeo: "A Francia nadie le da un subsidio." (Pedro Barrán)

Sucintamente cabe decir que el proceso en el cual se ha encaminado el Uruguay se presenta como marcado por rasgos propios de un modelo dependiente y que no ha encontrado en el viraje hacia la izquierda una impronta disímil a la traída desde gobiernos anteriores. La perspectiva adoptada de país anfitrión ha habilitado a los inversores extranjeros a modelar el país sin una dirección gubernamental o de modelo productivo preciso, desbordando la capacidad de respuesta y restricción de los ámbitos legislativos y quebrando la unidad de los equipos de gobierno, al interior de los mismos y en su vinculación con sectores de la sociedad civil, especialmente con sectores de impronta marxista y organizaciones de corte ambientalista. De esta forma la economía nacional se asienta sobre un vínculo foráneo mientras al interior del país (y en el ámbito regional) se producen y trasladan conflictos sociales que expresan el descontento entre un $\mathrm{PBI}$ en crecimiento, las condiciones sociales y salariales de los trabajadores y la orientación general del modelo de desarrollo que aparece como de "crecimiento desde afuera".

El principal objeto de este trabajo es brindar una lectura actual de un problema añejo, a saber, la dependencia del subdesarrollo hacia el desarrollo. La lectura realizada por los dependentistas clásicos que rompía con el dualismo de las sociedades mantiene su vigencia pues ha pasado medio siglo y podemos afirmar que el subdesarrollo es parte integrante del desarrollo. Si bien bajo un esquema de sistema mundo, o e concreto de economía mundo, pueden analizarse algunos corrimientos de los llamados estados periféricos, debe atenderse a que lo que es periférico o central, como bien señala Wallerstein, son los proceso productivos y no los países. En ese sentido el movimiento de los procesos productivos puede generar una ilusión de ascenso o de desarrollo, aún aceptando que al subir unos baja otros.

No obstante esta lectura, el movimiento de algunos procesos productivos, como sucede en el caso uruguayo, se dan en condiciones de estricta dependencia. El Uruguay se financia prácticamente con ahorro externo tanto a través de las inversiones como a través de endeudamiento público. Quienes invierten como quienes dan crédito, sea financiero o los llamados prestamos de desarrollo, cuentan con determinadas capacidades políticas y por tanto con la capacidad de someter la soberanía nacional. Históricamente se hablaba de las cartas intención del Fondo Monetario Internacional en la cual el organismo exigía reformas estructurales al sistema institucional de los países deudores; actualmente, y como refleja el contrato entre Uruguay y Montes del Plata, este tipo de acuerdos se extiende a agentes privados 
y corporaciones transnacionales que cobran el status de Estado nacional.

En el mismo sentido de atadura, las inversiones que mueven al país llegan, a su vez, con paquetes tecnológicos altamente centralizados y que remiten directamente a procesos productivos centrales: maquinaria, tecnología, insumos, know how, etc. Teniendo en cuenta que el modelo aquí analizado es e del agronegocio debe señalarse que el mismo implica variedades genéticas centrales, maquinaria importada de corporaciones transnacionales, experticia técnica formada por profesionales extranjeros, mano de obra especializada del exterior, capitales extranjeros y exoneraciones fiscales locales. En términos apresurados puede decirse que el país cede su tierra a operaciones extranjeras por lo que en términos de modelo de desarrollo debe realizarse una lectura de modelo dependiente. La evidencia presentada en este artículo permite vislumbrar un complejo panorama de un Uruguay dependiente y basado en un modelo de explotación de Recursos Naturales finitos sin lograr incorporar y apropiarse de los recursos importados y, al mismo tiempo, sin lograr reconvertir su matriz productiva en sectores que puedan ser impulsados y sostenidos endógenamente. La propuesta teórica del desarrollo desde dentro plasmada por Sunkel en la década del ' 80 y denominada neoestructuralismo no parece dar solución al problema identificado de romper con los lazos de dependencia.

En estos términos, se entiende que es útil y provechoso recuperar los aportes realizados bajo el problema teórico de la dependencia más allá de las diferentes escuelas y corrientes pues, si bien sus soluciones pragmáticas no tuvieron mayores éxitos, sus preguntas y sus diagnósticos se mantienen aún vigentes.

\section{Bibliografía referida}

- Alvarado, R. (2009) "La expansión forestal en el Cono Sur." Rev. Nueva Ciencia. Núm. 223. Pp. 76 a 93.

- Álvarez, J. F. (2006) "Economía de aglomeración: la distancia cognitiva en la creación de una empresa" Mimeo. Buenos Aires.

- Amin, S. (1989) "El eurocentrismo. Crítica de una ideología." Siglo XXI. México D.F.

- Bambirra, V y otros (1968) "Control político en el Cono Sur". Siglo XXI, México.

- Banco Central del Uruguay, Informes anuales de deuda externa. http://www.bcu.gub.uy/Estadisticas-e-Indicadores/Paginas/Default.aspx 
- Beigel, F. (2006) "Vida, muerte y resurrección de las teorías de la dependencia" en AAVV, Crítica y Teoría en el pensamiento social latinoamericano. CLACSO. Buenos Aires.

- Berman, M. (1988) "Todo lo sólido se desvanece en el aire." Siglo XXI. Ciudad de México.

- BERRlel, M; ESTAVILLO, Ma F; BONJOUR, L; (2011) "Empresas Transnacionales - Factores condicionantes para la inversión en Uruguay" Monografía de graduación FCEA: http://www.ccee.edu.uy/ensenian/catecap/2011-0630\%20ETFactoresCondicionantesDeLalnversionEnUruguay.pdf

- Bittencourt, G; Rodríguez, A; Torres, S. (2009) "Factores clave para el crecimiento económico sostenido en Uruguay" OPP. Serie Estrategia Uruguay Tercer Siglo - Documento No 01/09. Montevideo.

- Bitteoncourt, G.; Carracelas, G.; Doneschi, A.; Reig, N. (2009) "Tendencias Recientes de la Inversión Extranjera Directa en Uruguay." DECON, FCS, UdelaR. Mdeo.

- Brohman, J. (1996) "New directions in tourism for third world development." Annals of tourism research. 3 (1): 48 - 70.

- Carámbula, M. Y Piñeiro, D. (2006) "La forestación en Uruguay: cambio demográfico y empleo en tres localidades." Rev. Agrociencia. Vol X. N 2. Pp. 63 a 73. Montevideo.

- CEPAL, (2013). La Inversión Extranjera Directa en América Latina y el Caribe. Santiago de Chile

- Conde Hernández; R. (2000) "Corporaciones multinacionales y desarrollo económico: la inversión extranjera directa y las condiciones de su eficiencia productiva." En UNAM. Del fin del milagro al fin del milenio: Medio siglo de economía y política en México. Homenaje a José Luis Ceceña Gámez. Publicado por la Universidad Nacional Autónoma de México y la Universidad Autónoma de Sinaloa.

- Florit, P. (2013) "La cadena forestal celulósica, contexto para el puerto de La Paloma" en Piñeiro, D. (coord.) "Repercusiones de las inversiones forestales: la ampliación del puerto de la Paloma" Ed. CSICUdelaR, pp. 13-42.

- Florit, P. Y Piedracueva, M. (2013) "Hacia un Uruguay sin agricultura familiar." Rev. Olhares Sociais. Núm. 1. Volúmen 2.

- Florit, P. Piedracueva, M. (2012) Florit, P. y Piedracueva, M. "Turismo ¿para qué?" En Falero, A. y Campodónico, R. "El turismo bajo la lupa." Ed. CSIC - UdelaR. FSC

- (1994) "Principios y Criterios del FSC para el Manejo Forestal Responsable Con el Complemento de Notas Explicativas y Justificaciones." Disponible on line en: http://igi.fsc.org/md.static/FSC- 
STD-01-001_V5-0_D5-

O_ES_Notas_Explicativas+Justificaciones.pdfConsultado 12/11/2012.

- Graña, F. (2009) "Dialogo social y gobernanza. El discurso de los actores sociales involucrados en la instalación de la fábrica de celulosa en Fray Bentos."

- INASE (2010) "Control de comercio y estadística." Mdeo.

- Kaplan, M (1970) "Corporaciones públicas multinacionales, posibles contribuciones al desarrollo y planificación de América Latina" Comercio Exterior, agosto-setiembre 1970. México

- Kaplan, M (1972) "La ciudad latinoamericana como factor de trasmisión de poder socioeconómico y político hacia el exterior en la época contemporánea"S/D

- Kaplan, M. (1981) "Las características del nuevo orden político internacional" Nueva Sociedad, NRO. 55 JULIO-AGOSTO 1981, PP. 7-24

- Kaplan, M (1996) "El Estado Latinoamericano". UNAM, México

- Kaplan, M (2008) "Estado y globalización" Instituto de Investigaciones Jurícias, UNAM. México

- Kaplan, M (2000) "Regulación de flujos financieros Internacionales" Instituto de Investigaciones Jurídicas, UNAM. México

- Katz, C. (2014) "¿Qué es el neo-desarrollismo? I- Una visión crítica. Economía." Disponible en http://katz.lahaine.org/?p=232

- Lea, J. (1988) "Tourism and development in the third world."

Routledge. Londres.

- Martino, D. y Methol, M. (2008) "Cambios en el uso de la tierra." PNUMA, GEO Uruguay. Montevideo.

- Ministerio DE Economía Y Finanzas (2013) "Exportaciones de Bienes de Uruguay Composición, destinos y valor agregado" Serie "Estudios del Área de Política Comercial". Montevideo

- Nash, D. (1977) "Tourism as a form of imperialismo." En Smith, V. Hosts and guests: the anthropology of tourism. Elsevier. Amsterdam.

- Panario, D. Y Gutiérrez, O. (2007) "La política forestal industrial del estado uruguayo." UNCIEP - Facultad de Ciencias - UdelaR. Ponencia presentada al "Seminario: Política y pasteras en el Río Uruguay." Argentina.

- Paolino, C. (2010) "Uruguay: las políticas tecnológicas agropecuarias y el Plan Estratégico Nacional en Ciencia, Tecnología e Innovación (PENCTI)." En Anuario 2010 (pp. 245 - 266). OPYPA - MGAP. Mdeo.

- Paolino, C. Y PereraM. (2008) "Los factores explicativos de los niveles de pobreza rural." En La pobreza rural en el Uruguay. La situación actual 
y aportes para el diseño de una estrategia orientada a su combate(pp. $46-73)$. FIDA. Mdeo.

- Peluffo, A; (2011) "Integración regional y su relación con la dinámica de la splantas: un enfoque de diferencias en diferencias." INSTITUTO DE ECONOMIA; Serie Documentos de Trabajo; DT8/11. 2011. Facultad de Ciencias Económicas y Administración.

- Quijano, A. (1992) "Colonialidad y modernidad/racionalidad", en Perú Indígena, vol. 13, no. 29, Lima, 1992.

- Quijano, A. (2000) "Colonialidad del poder, eurocentrismo y América Latina." En Lander, E. Colonialidad del saber, eurocentrismo y ciencias sociales. CLACSO - UNESCO.

- Quijano, A. (2000) "Colonialidad del Poder y Clasificación Social" Journal of world-systems research, vi, 2, summer/fall 2000, 342-386

- Sunkel, O, et. al. (1991) El Desarrollo desde dentro. Un enfoque neoestructuralista para América Latina. 507 p. El Trimestre económico, México 1991. Introducción, capítulos 1, 2 y 3

- Sarli, V. (2004). "Impacto del cambio en el uso del suelo sobre el funcionamiento ecosistémico. Departamentos de Paysandú y Río Negro." Tesis de Maestría, Programa Ciencias Ambientales, Facultad de Ciencias. UDELAR. Montevideo.

- URUGUAY XXI (2012) "Informe de comercio exterior 2012." Mdeo.

- URUGUAY XXI (2014) Exportaciones Uruguayas por Capítulos. Estadísticas de Comercio Exterior. Mdeo.

- URUGUAY XXI b (2014) Informe de Comercio Exterior. Mdeo.

- Verger, A; (2003) "El sutil poder de las transnacionales Lógica, funcionamiento e impacto de las grandes empresas en un mundo globalizado" Icaria Editorial. Barcelona.

- Wallerstein, I (1998) Impensar las ciencias sociales. Límites de los paradigmas decimónicos. Siglo XXI, México.

- Wallerstein, I (2005) Análisis de Sistemas-Mundo. Una introducción. Siglo XXI, México. 